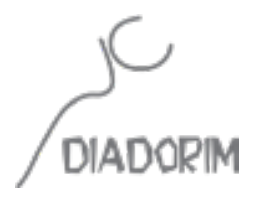

\title{
IMÁGENES DE UN CUERPO VACÍO: REPRESENTACIONES DE LAS MUJERES INDIAS DEL BRASIL (SIGLOS XVI Y XVII) ${ }^{1}$
}

\author{
Elena Losada Soler ${ }^{2}$
}

\section{RESUMÉN}

En los primeros textos portugueses sobre Brasil, donde el indio es el Otro, la india es doblemente Otra. Si las primeras europeas en América, salvo contadísimas excepciones, son un magma anónimo, sin espacio ni voz propia, cómo iba a ser mejor el destino y la situación de esas mujeres dos veces invisibles. Para intentar vislumbrar algo entre tanto velo, y aunque es premisa esencial para no repetir el equívoco de los indigenistas del siglo XIX y de los primeros etnólogos recordar que el "indio" como universal no existe y la "india" tampoco, debemos tener en cuenta que las representaciones de la mujer india del Brasil en los siglos XVI y XVII, especialmente las gráficas, se acercan mucho más a la representación de un universal que a una verdadera imagen individual.

PALAVRAS-CLAVE: Literatura; Mujer India; Imagen.

\begin{abstract}
In the first Portuguese texts about Brazil, where the Indian is the Other, the Indian is doubly Other. If the first Europeans in America, with very few exceptions, are an anonymous magma, with no space or voice of their own, how could the fate and the situation of these twice invisible women be better? To try to glimpse something among so many veils, and although it is an essential premise not to repeat the mistake made by 19th century Indians and the first ethnologists, to remember that the "Indian" as universal does not exist and neither does the "Indian", we must take into account that the representations of the Indian woman in Brazil in the 16th and 17th centuries, especially the printers, are much closer to the representation of a universal than to a true individual image.
\end{abstract}

KEYWORDS: Literature; Indian woman; Image.

\footnotetext{
1 Este artículo ya ha sido publicado in Escrituras de la sexualidad (Marta Segarra y Helena González Eds.), pp. 87-102, Icària, Barcelona, 2008. ISBN: 978-84-9888-036-6, D.L.: B-48.648-2008.

2 Professora Titular de Literatura Portuguesa na Universidade de Barcelona.
}

Diadorim, Rio de Janeiro, vol. 22, número 2, p. 30-41, 2020. 
Objetos que nos encaram: apontamentos sobre as relações entre sujeito e objeto no contexto...

El 22 de abril de 1500, cuando la flota de Pedro Álvares Cabral desembarcó en la costa nordeste del actual Brasil — un desvío en la elipse atlántica, casual o intencionado, los llevó hasta allí- su verdadero destino era la India. Asia era entonces el centro de atención primordial para los portugueses. A lo largo del proceso que condujo al establecimiento de la ruta de navegación hacia Oriente los portugueses se habían visto enfrentados a sucesivas formas de alteridad. Debido a que el contacto se estableció en fechas muy tempranas (desde la conquista de Ceuta en 1415 y a través de los mercaderes mauritanos) el África negra era para los portugueses lo “diferente- familiar". Asia Central y Extremo Oriente, referenciados ya desde las conquistas de Alejandro y más cercanos después del "siglo franciscano" y de las expediciones de los venecianos, eran lo "diferente-conocido", puesto que su existencia, más o menos envuelta en leyendas, formaba parte del acervo cultural europeo. Cuando el conocimiento más profundo de esa Asia legendaria estaba en sus inicios irrumpió el grado último de alteridad: América, lo "diferente-desconocido", donde no existían ni parámetros anteriores, ni vagas referencias geográficas, ni lenguas francas (PINTO, 1989, p. 221). Todo era nuevo y primigenio y esa imagen de alba del mundo domina las primeras visiones del territorio. Por eso América fue el escenario de todas las fantasías, sirvió para la creación de todas las utopías edénicas y, un poco más tarde, de todas las imágenes del infierno.

Todo primer contacto, ya sea en un viaje de exploración, de conquista, de colonización o de evangelización, supone el encuentro con estos diversos niveles de lo desconocido y en cada caso implica una forma específica de mirar esa nueva realidad según lo que se espere obtener de ella. Por eso el indio del Brasil mostrará múltiples rostros - objeto de evangelización, posible esclavo, molestia para la colonización o simple objeto de estudio - que son en realidad los de las intenciones de los europeos. A lo largo del siglo XVI pasará del edenismo a la demonización en los textos de propaganda para atraer colonos, donde el "Buen Salvaje" que no conocía los términos "ni tuyo ni mío", por usar las palabras de don Quijote en su discurso a los cabreros, se convierte en un monstruo cuya humanidad se pone en entredicho. El indio será entonces el "Monstruo Caníbal".

También la pintura portuguesa refleja esa transición, como podemos ver en la comparación entre el cuadro de Vasco Fernandes “Adoração dos Magos”, c. 1505, (Museu de Grão Vasco, Viseu), donde Baltasar es representado como un indio tupí en la que es posiblemente la primera representación plástica occidental de un indígena brasileño, y la pintura anónima "Inferno", c. 1530, (Museu de Arte Antiga, Lisboa), donde el demonio mayor presenta los rasgos de un indio.

¿Cuántos habitantes había en ese territorio que Álvares Cabral y los suyos llamaron "Terra da Vera Cruz", puesto que habían llegado en la Pascua? Las cuentas son difíciles de hacer con tribus nómadas la mayor parte de las cuales fueron diezmadas mucho antes de cualquier posibilidad de censo científico. Los historiadores ofrecen una horquilla amplísima de entre uno y cinco millones. No deja de ser tristemente significativo que ni una sola de las tribus tupíes sobreviviera a ese "encuentro" que fue en realidad un encontronazo (COUTO, 1995, pp. 60-65). La antropología

Diadorim, Rio de Janeiro, vol. 22, número 2, p. 30-41, 2020. 
divide a la población autóctona del Brasil en dos grandes grupos étnicos: el tronco macro-tupí y el tronco macro jê (COUTO, 1995, p. 52) Los europeos entraron en contacto con diversas tribus del tronco tupí que les transmitieron un desprecio por los jês (llamados tapuias en los textos de los portugueses) generado por siglos de guerras entre ellos. Así pues este Edén también tenía su serpiente. Y la mención al Edén no es una licencia poética porque los primeros europeos que arribaron a esa costa creyeron ver encarnadas las palabras de Ovidio, la Edad de Oro en su estado puro: temperaturas equilibradas todo el año; las frutas maravillosas, la presencia de los ríos inmensos que según la Biblia rodeaban el Paraíso o la presencia de papagayos, el único animal que conservó la facultad del habla después de la caída y que mantuvo la extrema longevidad del Paraíso perdido. Sérgio Buarque de Holanda, en su fundamental estudio sobre los elementos edénicos en la formación del imaginario sobre el Brasil, apunta una razón lógica para la salubridad atribuida a aquellas tierras: al desembarcar e incluir en la terrible dieta naútica frutos y productos frescos se producía una rápida mejoría: “[...] el restablecimiento radical, obtenido a veces en seguida del desembarco, se presentaba con todas las apariencias de un suceso misterioso y sobrenatural.” (BUARQUE DE HOLANDA, 1987, p. 345).

La descripción del indio brasileño que hacen estos viajeros de paso constituye la base del tópico del "Buen Salvaje" uno de los mitos más tenaces y más ideológicamente marcados de la cultura europea (WHITE, 1976, p. 121). El "Buen Salvaje" es una de las manifestaciones de la nostalgia del Edén en cualquiera de sus dos versiones, como Paraíso judeo-cristiano o como Edad de Oro greco-latina. Se trata pues de un tema íntimamente relacionado con las utopías, recordemos que las cartas de Vespucci sobre el Brasil interesaron mucho a Thomas More y que no por casualidad el marinero informante de Utopía es un portugués.

Esta idealización del indígena se basa en dos principios: belleza (cuerpo) e inocencia (alma). Pero mientras la descripción utópica del indio incide en su alma inocente e incluso en una cierta superioridad moral sobre el europeo corrupto la representación de la india se limita a la descripción de un cuerpo desnudo, vacío de toda cualidad o defecto. Sólo con la edad la india vieja, equivalente de la representación europea de la bruja, adquirirá un alma, un alma malvada de tejedora de conjuros y de directora de ceremonias antropófagas. Este es el núcleo esencial de la representación de la india. Cegados por esa desnudez tan contraria a su experiencia, los europeos sólo reflejaron cuerpos vacíos.

Podemos, sin embargo, establecer diferencias entre las diversas formas de mirar y de representar, porque ambos actos se realizan en función de una carga imaginaria propia de quien realiza ambas acciones y anterior a ellas. No es lo mismo mirar y representar cuando quien lo hace es un viajero ocasional, que está de paso en ese espacio y no tiene ningún proyecto de futuro para aquello que mira y representa, que mirar y representar cuando la intención es colonizar y, por lo tanto, necesariamente entrar en conflicto con el Otro que ocupa ese espacio deseado. Encontramos así formas muy diversas de llevar a cabo esos actos aparentemente tan simples: la del descubridor (Pero Vaz de Caminha, Antonio Pigafetta), la del colono (Pêro de 
Objetos que nos encaram: apontamentos sobre as relações entre sujeito e objeto no contexto...

Magalhães Gandavo, Gabriel Soares de Sousa), la del cautivo superviviente (Hans Staden), o la del misionero (Manuel da Nóbrega, José de Anchieta). Y como contrapunto a todas estas formas de mirar y de representar básicamente católicas debemos destacar también la perspectiva protestante de los hugonotes franceses que intentaron la aventura de crear en el Brasil una "Francia Antártica" (Jean de Léry).

La estancia de la expedición de Cabral duró diez días durante los cuales se produjo el primer contacto con los pobladores de aquella costa. Un contacto que, a diferencia de lo sucedido en otras situaciones de primer contacto, fue pacífico. Uno de los viajeros, Pêro Vaz de Caminha, un culto hidalgo de Oporto que viajaba a la India para ocupar el puesto de escribano en la fortaleza portuguesa de Calicut, levantó acta de lo que vio y en forma de carta la mandó al rey D. Manuel. Ese texto, la Carta do Achamento, es un documento esencial que, sin embargo, vio durante siglos usurpado su papel por las mistificaciones de Vespucci — la famosa Mundus Novus, por ejemplo - o por otro texto de la misma expedición pero mucho más simple y pobre: la Relação do Piloto Anónimo. La causa fue que la carta de Pêro Vaz de Caminha, quedó inexplicablemente olvidada en el archivo de la Torre do Tombo en Lisboa y sólo fue publicada en 1817. Este texto primordial es por lo tanto un documento invisibilizado que, siendo como es en realidad la primera mirada europea sobre el Brasil, no pudo intervenir en la creación del imaginario europeo sobre las nuevas tierras. Pese a ello su influjo en los historiadores y antropólogos contemporáneos ha compensado tres siglos de silencio.

La visión de Pero Vaz de Caminha es, como hemos dicho, la de un hombre cuyo verdadero destino es otro. Con toda su ambición puesta en la India, Caminha pasea su mirada de viajero en tránsito por la costa de Porto Seguro sin segundas intenciones de colonización o de conquista. En muchos aspectos, como afirma Rocha Pinto (PINTO, 1989, p. 231), la Carta es un ejemplo diáfano de "littérature du regard" en la que todo gira alrededor de un hombre que mira a otros seres humanos con una mirada sin propósito ulterior. Y esa es también la actitud con la que Pêro Vaz de Caminha describe a las mujeres que se acercan a la playa. La primera descripción que hace que ve crea un patrón que se repetirá con muy pocas variantes en todo el texto:

Allí andaban entre ellos tres o cuatro mozas, jóvenes y gentiles, con los cabellos muy negros y largos por los hombros y sus vergüenzas tan profundas, tan cerradas y tan limpias de pelo que, a pesar de mucho mirarlas no teníamos ninguna vergüenza. ${ }^{3}$ (CAMINHA, 1967, p. 231)

Destaquemos en esta cita los componentes de la representación: la juventud y la desnudez, elementos edénicos, pero que también las convierten en objeto de deseo sexual. Esta tensión implícita queda reforzada por la referencia a la "vergüenza" en el doble sentido del término: la vergüenza moral que los portugueses no sienten al mirarlas porque en ellas no hay nada de provocador, pero también la referencia directa a "las vergüenzas" de ellas, es decir a sus

3 La traducción de las citas es nuestra.

Diadorim, Rio de Janeiro, vol. 22, número 2, p. 30-41, 2020. 
genitales. La descripción primera es, pues, claramente sexual aunque se revista de edenismo. La mención de los largos cabellos, un símbolo clásico en la tradición occidental (BORNAY, 1994, p. 15), acentúa el elemento subyacente a toda esta construcción aparentemente inocente.

Toda representación de lo nuevo en un primer contacto se hace siempre en relación a lo conocido, ya sea por analogía - las cosas "son como"- o por contraste, "son al revés de". En el caso de Cabral y sus hombres el punto de referencia son las mujeres mediterráneas y las africanas. Cuando Vaz de Caminha insiste en los largos cabellos de las indias está marcando una descripción por contraste con las mujeres de África y aproximándolas a una imagen europea de lo "deseable". Veamos otra cita que complementa lo anteriormente expuesto:

Y una de aquellas jóvenes estaba completamente teñida de aquella pintura $\mathrm{y}$ en verdad era tan bien hecha y tan redonda, y su vergüenza (que ella no tenía) tan graciosa, que a muchas mujeres de nuestra tierra, viéndola, les daría vergüenza no tener la suya como la de ella. (CAMINHA, 1967, p. 232)

Sólo cuatro años después de la expedición de Cabral el capitán normando Binot Paulmier de Gonneville, desviado de su viaje a la India por una gran tormenta, arribó a la costa del Brasil. En el texto de Gonneville los indios ya no son todos iguales, aparecen divididos en buenos (carijó) y malos (tupinambá), naturalmente según cuál fuera su actitud hacia los franceses. Esa división tiene importancia cuando se trata de describir a las mujeres. En el caso de las carijó no se enfatiza para nada una desnudez que sería en este caso sentida como salvajismo y no como inocencia: "[...] y las mujeres collares y brazaletes de oro y de conchas [...] y las mujeres y las jóvenes llevan la cabeza descubierta [...].” (GONNEVILLE, 1995, p. 21). En cambio la desnudez de los tupinambá acentúa su salvajismo: "[...] desnudos como salieron del vientre de su madre, hombres y mujeres, bien poco les cubre el cuerpo, [...]" (GONNEVILLE, 1995, p. 26).

En 1519 la flota de Magallanes en su busca del camino occidental hacia las Molucas recaló en el Brasil. Antonio Pigafetta, cronista de la expedición, introduce otro

elemento: en este Paraíso alternativo, el mal - la antropofagia en este caso - entró también a través de una mujer, en este caso una vieja — el doble mal— vengativa:

Esta costumbre [la antropofagia] empezó cuando el hijo único de una vieja fue asesinado por sus enemigos. Cuando pasaron unos días algunos de los suyos apresaron a uno de los compañeros del que había matado al hijo y lo condujeron a donde estaba la vieja. Ella, al verlo, se acordó de su hijo y como una perra rabiosa saltó encima de él y le mordió en un hombro. (PIGAFETTA, 1999, p. 84-85)

La antropofagia será uno de los temas recurrentes - junto con la descripción de la fauna y flora - de estos primeros textos. De ellos proceden en gran parte las referencias al canibalismo entre estas tribus de la costa, hoy - recordémoslo- desaparecidas. Según estos testimonios el canibalismo ritual era común entre las tribus tupíes — potiguaras, caetés, tupinambás, 
Objetos que nos encaram: apontamentos sobre as relações entre sujeito e objeto no contexto...

tupiniquins y tamoios - mientras que los pueblos jê practicarían el más básico canibalismo alimentario. Debemos tener en cuenta, sin embargo, que fueron los tupíes, enemigos ancestrales de los jê, quienes transmitieron a los europeos buena parte de sus conocimientos etnológicos.

Todas las descripciones de rituales antropofágicos en la costa del Brasil en los textos de los siglos XVI y XVII refieren la importancia de las viejas en esas ceremonias. Ellas eran las encargadas de recoger en un recipiente la sangre y la masa encefálica, la misma sangre que en el también ritualizado reparto de las partes —a los niños los intestinos, a los hombres el corazón, por ejemplo - les correspondía. Una vez más la máxima maldad es atribuida a lo femenino.

Hans Staden, un arcabucero de Hesse, llegó al Brasil al servicio de Diego de Sanabria, gobernador del Río de la Plata. En una escaramuza fue hecho prisionero por los tupinambás que lo retuvieron nueve meses bajo amenaza constante de ser comido. Tras ser rescatado por un barco francés regresó a Europa y en 1557 se publicó en Marburg su historia, que se convirtió en un verdadero best-seller. En ella Staden cuenta en primera persona su captura y su vida cotidiana como futuro banquete en el poblado tupinambá. El festín fue retrasándose y, tras meses de cautiverio en los que llegó a establecer curiosos lazos de amistad con sus captores cuando una epidemia le permitió mostrar sus habilidades como "médico"-aunque este es un motivo legendario y recurrente en este tipo de relatos-, fue rescatado. Pese a que en el texto los tupinambá son siempre llamados "los salvajes" y a que, obviamente, no parece que a priori vaya a ser su mayor defensor, Staden no muestra en ningún momento el odio o el desprecio al Otro que caracterizan a los textos de los colonos. Su actitud resulta especialmente meritoria cuando pensamos en su situación, la de un europeo que se ve reducido a la animalidad —en la peor de sus formas, la de servir de comida - por un "salvaje". Esa gigantesca humillación — le afeitan la barba y las cejas - se ve agravada porque eran las mujeres las agentes de la ofensa: "Estaban ahí muchas de ellas, que arrancaban raíces, y tuve que gritarles en su lengua: "Aju ne xe peê remiurama", es decir: "Estoy llegando yo, vuestra comida" (STADEN, 1974, p. 87). Todos los presupuestos de la jerarquía europea se veían así alterados. Staden nos deja también una interesante descripción de un rol femenino, el de vehículo del misterio, cuando tras una ceremonia que recuerda aún a las actuales del candomblé, la magia del hechicero les otorga la capacidad de profetizar. La mujer no tiene, pues, acceso a la gran magia pero sí puede ser su intermediaria:

Primeramente van los salvajes a una choza, toman una después de otra a las mujeres de la habitación y las inciensan. Después cada una debe gritar, saltar y correr en círculos hasta que está tan cansada que cae al suelo como muerta. Entonces dice el hechicero: "Mirad ahora está muerta. Luego la devolveré a la vida". Cuando vuelve en si, dice él, es apta para predecir cosas futuras, y cuando después partan a la guerra deberán profetizar sobre ella. (STADEN, 1974, p. 175)

Treinta años después de la experiencia de Hans Staden la "Terra do pau brasil" se había convertido en un lugar económicamente apetecible. La tierra se había dividido en donatarias

Diadorim, Rio de Janeiro, vol. 22, número 2, p. 30-41, 2020. 
y en ellas proliferaban las plantaciones, Entonces la visión del indio cambió completamente, de "Buen Salvaje" pasó a "Bárbaro Caníbal" porque era necesario poder entablar una "guerra justa" que permitiera esclavizarlos y apoderarse de la tierra. En esta línea se sitúan los textos destinados a atraer colonos al Brasil, textos de equilibrio delicado porque era necesario atacar al indio pero no cargar demasiado las tintas sobre el tema del canibalismo porque eso podría tener efectos disuasorios.

Un ejemplo de esta actitud es la que encontramos en los textos de Pêro de Magalhães Gandavo - por otra parte un notable humanista, amigo de Camões-: Tratado da Terra do Brasil (1570, publicado en 1826) y História da Província Santa Cruz (1575). En sus escritos las "aves inocentes del paraíso" de Caminha se han convertido en "brutos animales". Ellos no han cambiado pero la intención del europeo que los mira sí. Un ejemplo de esta distorsión de la mirada lo encontramos en un pasaje muy conocido: "La lengua de estos infieles es una en toda la costa: le faltan tres letras, es decir, no se encuentra en ella ni F, ni L, ni R, cosa digna de maravilla, porque por eso no tienen Fé, ni Ley, ni Rey y viven sin justicia y desordenadamente." (GANDAVO, s.d., p. 49). Es decir, una característica lingüística del tupí, distorsionada por Gandavo, sirve para extraer unas extrapoladas características morales destinadas a crear una imagen diabólica del indio. Esta demonización se concreta en la detallada descripción de la antropofagia, donde una vez más aparece la "india vieja", como antonomasia del mal: “[ ...] y entonces lo matan y lo hacen pedazos. Y está ahí una india vieja con un cesto en la mano y así que cae va muy deprisa a ponérselo en la cabeza para tomar los sesos y la sangre [...]" (GANDAVO, s.d., p. 49).

También en su texto, cuando describe a la tribu enemiga de los aymorés, encontramos, por primera vez, a las amazonas, el tema clásico que con tanta fortuna viajó al Nuevo Mundo, imagen del mal por la absoluta subversión de los roles de género que su forma de vida implica y por el lesbianismo que se insinúa:

Algunas indias de estos lugares juran y prometen castidad y no se casan ni conocen hombre ni lo consentirían aunque las matasen. Estas dejan todo el ejercicio de mujeres e imitan a los hombres y siguen sus oficios como si no fuesen mujeres y se cortan el pelo a la manera de los machos y van a la guerra con arcos y flechas y a cazar: en fin que andan siempre en compañía de los hombres, y cada una tiene mujer que la sirve y que le prepara la comida como si estuviesen casados. (GANDAVO, s.d., p. 54)

En el monumental Tratado descriptivo del Brasil (1587), de Gabriel Soares de Sousa, también colono, encontramos otra referencia a las amazonas, más matizada y relacionada con el mito: “[ [...] y por la otra con unas mujeres, que dicen que sólo tienen un pecho, que pelean con arco y flecha, y se gobiernan y rigen sin maridos, como se dice de las Amazonas; de los cuales no pudimos alcanzar más información, ni de la vida y costumbres de estas mujeres." (SOUSA, 1938, p. 413). Es significativo que en las más de quinientas páginas de su tratado, cuando Gabriel Soares de Sousa describe a los indios nunca menciona de forma específica a las

Diadorim, Rio de Janeiro, vol. 22, número 2, p. 30-41, 2020. 
Objetos que nos encaram: apontamentos sobre as relações entre sujeito e objeto no contexto...

mujeres. Sólo se las menciona en los apartados de relaciones familiares y afeites y, como no, en el capítulo "Que trata de la lujuria de estos bárbaros (CLVI)". Por otra parte observamos que en los textos que están ya lejos del primer contacto la desnudez ha dejado de ser un tema relevante

Entre los elementos legendarios que convienen a su propósito Gandavo y Soares deslizan algunas notas etnológicas reales de gran interés, como por ejemplo la descripción de la "covada", costumbre que para un europeo del siglo XVI solo podía significar ignorancia y salvajismo, a la vez que situaba al indio en la más absoluta alteridad: "Cuando estas indias paren la primera cosa que hacen después del parto es lavarse en un río y quedan tan bien como si no hubiesen parido; en su lugar se acuestan sus maridos en las hamacas y así los visitan y cuidan como si fuesen ellos la parturienta." (SOUSA, 1938, p. 413).

Poco queda, pues, de la mirada maravillada de Caminha sobre los largos cabellos de las indias en estos textos de finalidad tan distinta. También en las cartas del Pe. Manuel da Nóbrega, director de la primera misión jesuítica que se estableció en Brasil a partir de 1549, encontramos una opinión muy alejada de la del escribano. El "Buen Salvaje" es una imagen casi pagana de inocencia y de desconocimiento de la culpa que difícilmente los ideólogos de Trento y de la doctrina del pecado original podrían aceptar. Para Manuel da Nóbrega el indio está siempre inclinado al mal, dominado por apetitos sensuales y desconoce la verdad de Dios, lo que era una fuente de preocupación para los misioneros católicos. Pese a todo no desistieron y, frente a las dudas expresadas por Nóbrega en su Diálogo sobre a Conversão do Gentio, José de Anchieta afirmaba que todas las dificultades para la conversión se solucionarían "si hubiera temor y sujeción [...] porque obligarlos a juntarse y a tener una iglesia bastó para que recibiesen la doctrina de los Padres [...]" (ANCHIETA, 1988, p. 341). He aquí el origen de la filosofía de las "reducciones". El nomadismo era el principal problema y su mejor combate colocarlos donde no pudieran huir de la "verdadera fe".

Para los jesuitas la mujer es esencialmente el diablo tentador, la agente activa de aquella libertad sexual que les horrorizaba: "[...] porque es costumbre hasta ahora entre ellos no hacer caso del adulterio, tomar una mujer y dejar a otra, como bien les parece y sin tomar nunca ninguna en firme.” (NÓBREGA, 1988, p. 93). Las cartas jesuíticas están repletas de menciones a las costumbres licenciosas incitadas por las mujeres y a sus efectos disolventes sobre los portugueses recién llegados. Precisamente para apartarlos de esas Evas exóticas Manuel da Nóbrega solicitó al rey de Portugal que enviase huérfanas al Brasil, para que los colonos pudiesen constituir familias cristianas. Cuando la remesa de huérfanas no es suficiente Nóbrega está dispuesto a casar a los portugueses con indias cristianizadas, acogidas en "casas de redimidas": "Las indias libertas que hace mucho que andan con los cristianos en pecado trabajamos para evitar que se vayan al bosque porque son cristianas y hemos creado una casa a costa de sus amos para recibirlas en ella e irlas casando poco a poco con algunos hombres trabajadores." (NÓBREGA, 1988, p. 119). 
La misma ceremonia que relataba Staden en la cual las mujeres poseídas por los espíritus desatados por el hechicero obtenían el don de la profecía, adquiere, narrada por Nóbrega, otra dimensión, la de una posesión diabólica. ¿Acaso no eran las mujeres más sensibles que los hombres al influjo del diablo?, al menos así consta en todos los procesos por brujería que asolaron Europa y los Estados Unidos: “Acabando de hablar el hechicero, empiezan a temblar, principalmente las mujeres, con grandes temblores en todo su cuerpo, que parecen endemoniadas (como seguramente lo son) [...]” (NÓBREGA, 1988, p. 99).

Frente a las mujeres malvadas, Liliths y Evas, Nóbrega no olvida a las "Marías" porque ya en 1550 había en Brasil "mártires virtuosas": "Hay ya indias esclavas de cristianos, que, amonestadas en las confesiones para que no pequen con sus señores ni con nadie, antes se dejan golpear y matar antes que volver al pecado pasado." (NÓBREGA, 1988, p. 161). José de Anchieta, más plástico y mejor escritor que Nóbrega, deja una imagen más impactante de estas mártires: "[...] queriendo el que la había capturado tomarla por amante nunca lo consintió ni con halagos ni con amenazas, hasta que decidió matarla a lo que ella se ofreció de buena gana para no ofender a Dios, y estando ya su señor en ello, lo impidieron sus otros parientes." (ANCHIETA, 1988, p. 203).

Pero ni siquiera Anchieta, sin duda el mejor conocedor de la realidad indígena de la primera generación de misioneros, vacila al atribuir a la mujer todos los males, desde la corrupción del cuerpo: "La visitaban muchas veces los Hermanos, la consolaban con las divinas palabras, principalmente cuando, ya al final, cuando tenía corrompidos los miembros secretos (esta era su enfermedad, que es muy común en estas mujeres del Brasil, incluso en las vírgenes) [...]” (ANCHIETA, 1988, p. 158), a la práctica de abortos: “[...] o con cualquier otro motivo muy ligero matan a sus hijos; o bebiendo para eso algunas bebidas; o apretando la barriga, o llevando una carga grande y de otras muchas maneras que la crueldad inhumana inventa [...]"(ANCHIETA, 1988, p. 159).

Frente a la visión de los jesuitas se sitúa la visión de los protestantes franceses huidos en 1556 bajo el mando de Villegaignon en busca del sueño de una nueva patria. La utopía fue breve y acabó mal pero dejó algunos textos importantes, en especial Histoire d'un Voyage faict en la Terre du Brésil (1578) de Jean de Léry. Se trata de un texto fuertemente ideologizado en el cual los tupinambás son usados como espejo contrastivo y como instrumento de crítica hacia la decadente Francia católica que han abandonado:

No hay que horrorizarse tanto de la crueldad de los salvajes antropófagos, es decir, comedores de hombres, porque hay otros como ellos, incluso más detestables y peores entre nosotros que aquellos que, como se ha visto, sólo se arrojan sobre las naciones que son sus enemigas, mientras que los de aquí se tiran a la sangre de sus parientes, vecinos y compatriotas. (LÉRY, 1994, p. 377)

Precisamente por ese uso complejo de la imagen del indio la descripción de Léry es 
Objetos que nos encaram: apontamentos sobre as relações entre sujeito e objeto no contexto...

precisa y extensa y contiene tópicos clásicos como el de su extraordinaria longevidad o el de la inocente desnudez de los indios, usados ahora como arma en la polémica sobre el pecado original. También en la concreta descripción y valoración de la mujer india Jean de Léry incorpora elementos originales, por ejemplo presentarnos la mirada del Otro. Desde el texto de Caminha es siempre el europeo quien mira al indio, en el de Léry el indio mira a la europea, vestida, y siente la misma estupefacción que los europeos ante la desnudez: “[...] pero también porque muchos salvajes, que habían venido a vernos, se quedaron atónitos al ver a las mujeres vestidas (porque antes no las habían visto nunca) [...]”. (LÉRY, 1994, p. 179).

Léry sabe que la desnudez puede ser más inocente que el vestido, y elabora una verdadera teoría del deseo:

Antes de cerrar este capítulo es necesario responder a los que piensan que el contacto con estos salvajes desnudos, y especialmente con las mujeres, incita a la lubricidad y al desenfreno. Sobre esto diré brevemente que aunque en apariencia hay demasiada ocasión de deshonestidad al ver a estas mujeres desnudas, esto no sirve en realidad para excitar el apetito del deseo porque, como hemos observado repetidamente, la desnudez grosera de estas mujeres es menos atractiva de lo que podríamos pensar. Y, no obstante, mantengo que los pliegues, verdugados, gorgueras y otras infinitas bagatelas que las mujeres de allá usan sin que les parezcan nunca suficientes son sin comparación causa de más males que la simple desnudez de estas mujeres, que, sin embargo, no tienen nada que envidiarles en cuanto a belleza. (LÉRY, 1994, p. 234).

Pero no sólo los textos nos han dejado representaciones de la mujer india, los ilustradores son también fuentes de información interesantísimas y cargadas de sentido, porque la imagen no está más libre de apriorismos que la palabra. Las primeras grandes ilustraciones sobre el Brasil se encuentran en el tomo III de los monumentales trece volúmenes de Grands VoyagesAmericae publicados entre 1590 y 1634 por Théodore de Bry y sus herederos Jean Théodore y Jean-Israel de Bry. Ninguno de estos artistas, descendientes de una familia de famosos orfebres, estuvo nunca en Brasil; sus grabados se basan en los relatos de los viajes de Staden, Léry, Benzoni y Bartolomé de las Casas. La suya es pues una América filtrada por una perspectiva claramente eurocéntrica, como vemos claramente en sus representaciones de mujeres indias, que son presentadas - incluidas las amazonas - con los rasgos de las mujeres de Rubens, altas, entradas en carnes de cabellos ondulados y rubios, representación que responde por otra parte al imaginario erótico masculino de la época. De este modo las indias brasileñas fueron para los europeos, a través de los suntuosos álbumes de los de Bry, una especie de campesinas flamencas bellas - excepto las terribles viejas, naturalmente - y desnudas.

Poco después de los grabados de los de Bry llegaron a Europa nuevas imágenes de las mujeres de América. Venían de la mano del holandés Albert Eckhout (1610-1665), que formó parte de una expedición holandesa que acompañó entre 1637 y 1644 a Juan Mauricio de Nassau, al nordeste del Brasil, entonces zona de conflicto entre portugueses y holandeses; con ellos iban también otros pintores como Franz Post (1612-1680), Zacharias Wagener (1614-1668) y

Diadorim, Rio de Janeiro, vol. 22, número 2, p. 30-41, 2020. 
Albrecht Willaerts (1603-1669). La obra de Eckhout presenta un interés especial para nuestro estudio dado que pintó allí mismo 18 telas, de las que se conservan 7, tituladas Rerum per octennium in Brasilia (1647). A su regreso Nassau le encargó una serie de pinturas mostrando las maravillas de América y Eckhout creó ocho pinturas de nativos, animales y plantas que sirvieron de base para muchos tapices de Gobelinos llamados "Les anciennes Indes" y tuvieron una gran difusión. La india de Eckhout ya es verosímil físicamente pero no ha perdido el apriorismo: de la cesta "de la compra" que lleva a la espalda sobresale un pie humano, en clara alusión a la antropofagia.

Finalmente, y como contraste con esa constante representación de una india universal y vacía, recordemos algunos nombres propios, los poquísimos que nos han llegado: Maria do Espírito Santo Arcoverde (Muíria-Ubi), hija del jefe tabajara Arcoverde, concubina de Jerónimo de Albuquerque, padre de al menos treinta hijos, conocido como el "Adán pernambucano"; Maria da Grã (Terebé), hija del cacique Tebiriçá, convertido al cristianismo, que se empeñó en casarla con Pero Dias, un fraile lego jesuita a quien el propio Ignacio de Loyola liberó de sus votos para favorecer las buenas relaciones con los indios; y, sobre todo, Catarina Álvares (Paraguaçu), hija de un cacique tupinambá de la zona de Bahía, casada con Diogo Álvares "Caramuru", un náufrago que vivió toda su vida con los tupinambás y sirvió de intérprete entre los indios y los portugueses. El indigenismo romántico, inspirándose en el poema épico Caramuru (1781) de Frei José de Santa Rita Durão (1722-1784), convirtió a Diogo Álvares en una de las figuras míticas en la construcción del Brasil. Ninguna de estas mujeres alcanzó la ambigua fama de la Malinche, pero ese puñado de nombres rescatados de las crónicas y las vidas que intuimos tras ellos nos dicen más que los textos y los grabados; sin eliminar el vacío lo llenan de ecos.

\section{Referências}

ANCHIETA, J. de (1554-1594). Cartas, Informações, Fragmentos Históricos e Sermões. São Paulo: Ed. da Universidade de São Paulo, 1988.

BORNAY, E. La cabellera femenina. Madrid: Cátedra, 1994.

CORTESÃO, J. A carta de Pêro Vaz de Caminha. In: . Obras Completas de Jaime Cortesão XIII. Lisboa: Portugália Editora, 1967.

COUTO, J. A Construção do Brasil. Lisboa: Edições Cosmos, 1995.

GANDAVO, P. de M. (1570-1575). Tratado da Terra do Brasil. História da Província Santa Cruz. Rio de Janeiro: Edição do Anuário do Brasil, s.d.

GONNEVILLE, B. P. de (1505). Le voyage de Gonneville. Paris: Éditions Chandeigne, Paris, 1995. 
Objetos que nos encaram: apontamentos sobre as relações entre sujeito e objeto no contexto... Felipe Vilmar da Motta Veiga

HOLANDA, S. B. de. Visión del Paraíso. Motivos Edénicos en el Descubrimiento y Colonización del Brasil. Caracas: Biblioteca Ayacucho, 1987 [1959].

LÉRY, J. de. Histoire d'un voyage faict en la terre du Brasil (1578). Texte établi, présenté et annoté par Frank Lestringant]. Paris: Le Livre de Poche-Bibliothèque Classique, 1994.

NÓBREGA, M. da (1549-1560). Cartas do Brasil. São Paulo: Ed. da Universidade de São Paulo, 1988.

PIGAFETTA, A. (c. 1530). El primer viaje alrededor del mundo, [Ed. de Isabel de Riquer]. Barcelona: Ediciones B, 1999.

PINTO, J. R. Em viagem: a descoberta da alteridade. A invenção do índio brasileiro. In: A Viagem. Memória e Espaço. Lisboa: Livraria Sá da Costa, 1989, pp. 217-239.

SOUSA, G. S. de (1587). Tratado Descriptivo do Brasil em 1587. [Ed. de Francisco Adolfo Varnhagem]. Rio de Janeiro: Compañía Editora Nacional, 1938.

STADEN, H. (1557). Duas Viagens ao Brasil. São Paulo: Ed. da Universidade de São Paulo, 1974.

WHITE, H. The Noble Savage. Theme as Fetish. In: CHIAPELLI, F. (Ed.) First Images of America. The Impact of the New World in the Old. California: University of California Press, Berkeley, 1976. 